\title{
Food intake and weight of lactating rats maintained on different protein-calorie diets, and pup growth
}

R.P.B. Cambraia ${ }^{1}$,

H. Vannucchi ${ }^{2}$ and

L.M. De-Oliveira ${ }^{1}$

\author{
${ }^{1}$ Departamento de Psicologia, Faculdade de Filosofia, Ciências e Letras, and \\ ${ }^{2}$ Departamento de Clínica Médica, Faculdade de Medicina, \\ Universidade de São Paulo, 14049-900 Ribeirão Preto, SP, Brasil
}

\section{Correspondence \\ L.M. De-Oliveira \\ Laboratório de Nutrição \\ e Comportamento \\ Departamento de Psicologia \\ FFCLRP, USP \\ Av. Bandeirantes, 3900 \\ 14049-900 Ribeirão Preto, SP \\ Brasil \\ Fax: 55 (016) 633-6361 \\ E-mail: Imaroliv@usp.br \\ Research supported by FAPESP and CAPES.}

Received March 21, 1997 Accepted June 26, 1997

\begin{abstract}
Studies on rats maintained on low-protein-calorie diets during the lactation period show that food intake decreases. This process results in weight loss and a delay in litter development. The purpose of the present study was to determine the alterations in food intake, maternal weight and litter growth during lactation when dams were exposed to diets with different levels of protein and carbohydrate. Female Wistar rats receiving one of 4 different diets, $A(N=14), B(N=14), C(N=$ $9)$ and $\mathrm{D}(\mathrm{N}=9)$, were used. Diet A contained $16 \%$ protein and $66 \%$ carbohydrate; diet B, $6 \%$ protein and $77 \%$ carbohydrate; diet C, $6 \%$ protein and $66 \%$ carbohydrate; diet D, $16 \%$ protein and $56 \%$ carbohydrate. Thus, $\mathrm{C}$ and $\mathrm{D}$ diets were hypocaloric, while $\mathrm{A}$ and $\mathrm{B}$ were isocaloric. The intake of a low-protein diet in groups $\mathrm{B}$ and $\mathrm{C}$ affected the weight of dams and litters during the last two weeks of lactation, while the low-calorie diets limited the growth of $\mathrm{D}$ litters at 21 days compared with A litters, but had no effect on the weight of D dams. Group B showed an increase in intake during the first five days of lactation, resulting in a behavioral calorie compensation due to the increase in carbohydrate content, but the intake decreased during the last part of lactation. Food intake regulation predominantly involves the recruitment of a variety of peripheral satiety systems that attempt to decrease the central feeding command system.
\end{abstract}

Key words

- Lactation

- Malnutrition

- Low-protein-calorie diet

- Feeding behavior

- Weight and growth of rats
The increase of food intake during a normal lactation period in rats is the result of high energy requirements associated with the process of milk synthesis. The increased meal frequency during the daytime in the second and third postpartum weeks shows that at extremely high rates of energy expenditure, rats are capable of changing their feeding pattern (1). When lactating rats are subjected to severe malnutrition or offered imbalanced diets (low-protein-high-energy) that suppress food intake, milk production may be impaired due to metabolic changes including muscle protein degradation (2). The study of malnutrition during the lactation period shows that a decrease in food intake involves gastrointestinal and neural regulation.

The purpose of the present study was to determine the alterations in food intake, maternal weight and litter growth during lactation when the dams were exposed to 
diets with different levels of protein and carbohydrate.

Female Wistar rats from the Central Animal House, University of São Paulo at Ribeirão Preto, were used. After birth the mothers received one of 4 different diets, $A$ $(\mathrm{N}=14), \mathrm{B}(\mathrm{N}=14), \mathrm{C}(\mathrm{N}=9)$ and $\mathrm{D}(\mathrm{N}=$ 9), as shown in Table 1. Banana extract was used to standardize the flavor and taste of the diets. Cellulose (carboxyl methyl) was used as a neutral component since it is not metabolized by rodents and therefore does not contribute energy to the diets, but it may alter food intake patterns and caloric intake due to diet deficiency. Thus, $\mathrm{C}$ and $\mathrm{D}$ are hypocaloric diets. The animals were maintained on a 12-h light-dark cycle, with lights on at 6:00 a.m. The temperature was maintained at $23-25^{\circ} \mathrm{C}$.

Each dam received 6 male pups obtained from a larger litter pool and weaning occurred at 21 days postpartum. Each dam and litter were housed in an individual acrylic cage $(40 \times 33 \times 16 \mathrm{~cm})$ with free access to water and feeding cups. The nestling wood shavings were changed each week. The food container was placed $9 \mathrm{~cm}$ above the cage floor, preventing the pups from eating the diet of the dams during the early lactation period. Maternal and litter weight, and diet

Table 1 - Protein carbohydrate and cellulose content (\%) of diets offered to dams during lactation.

Banana extract was administered as $1 \%$ of each formulation. ${ }^{1}$ Dyets Inc., USA (high nitrogen casein, 85.55\%); ${ }^{2}$ maize starch (Maizena ${ }^{\circledR}$ ); ${ }^{3}$ Mazola ${ }^{\circledR}$; ${ }^{4}$ AIN 76, American Institute of Nutrition Rodent Diets 1976 (Ref. 3); ${ }^{5}$ AOAC, Association of Official Agricultural Chemists 1960 (Ref. 4); ${ }^{6}$ Carboxyl Methyl Cellulose ${ }^{\circledR}$.

\begin{tabular}{lcccc}
\hline $\begin{array}{l}\text { Component } \\
\text { (\% dry weight) }\end{array}$ & Diet A & Diet B & Diet C & Diet D \\
\hline Casein $^{1}$ & $18.7(16.0)$ & $7.01(6.0)$ & $7.01(6.0)$ & $18.7(16.0)$ \\
Carbohydrate $^{2}$ & 66.1 & 77.8 & 66.1 & 56.2 \\
Corn oil $^{3}$ & 8.0 & 8.0 & 8.0 & 8.0 \\
Mineral mix $^{4}$ & 5.0 & 5.0 & 5.0 & 5.0 \\
Vitamin mix $^{5}$ & 1.0 & 1.0 & 1.0 & 1.0 \\
L-Methionine $^{1}$ & 0.04 & 0.02 & 0.02 & 0.04 \\
Choline $^{1}$ & 0.20 & 0.20 & 0.20 & 0.20 \\
Cellulose $^{6}$ & 1.0 & 1.0 & 12.71 & 10.91
\end{tabular}

consumption were recorded each morning. Spillage was weighed to determine the precise food intake.

All data were tested for normality of distribution. When appropriate, nonparametric statistical tests were used. Data about dam and litter weight, and food intake were analyzed by a one-factor, repeated-measures ANOVA. Comparisons between groups were made by the Student-Newman-Keuls test or Dunn's test. The Student $t$-test was used to compare the bomb calorimetric energy measurements of the diets. The level of significance was set at $\mathrm{P}<0.05$ and all statistical analyses were carried out using the SigmaStat version 2.0 software package of Jandel Scientific (San Rafael, CA, USA).

Analysis of dam weight, litter weight and diet intake at the beginning of lactation (day 0) did not show significant differences between groups A, B, C and D. The weight of dams and litters of groups $B$ and $C$ were similar, but lower than those observed for groups $\mathrm{A}$ and $\mathrm{D}(\mathrm{P}<0.05)$ on days 7,14 and 21. A and D dams maintained the same weight during lactation, but $\mathrm{D}$ litters showed lower weights $(210.1 \pm 8.8, \mathrm{P}<0.05)$ than $\mathrm{A}$ litters $(245.9 \pm 5.4)$ at day 17 . At day 21 , the average weight of dams and the standard error were $281.8( \pm 6.1), 203.5( \pm 8.0), 224.6$ $( \pm 8.4)$ and $278.6( \pm 6.9)$ for groups A, B, C and $\mathrm{D}$, respectively, while litter weight was $309.0( \pm 8.0), 127.7( \pm 8.5), 104.9( \pm 3.8)$ and $236.1( \pm 11.5)$. When compared to group A, litters B and C showed a reduction of $41 \%$ and $34 \%$ in weight at the end of the lactation period. Groups $\mathrm{A}$ and $\mathrm{D}$ showed greater diet ingestion than groups $\mathrm{C}$ and $\mathrm{B}(\mathrm{P}<0.05)$, i.e., nitrogen and calorie intake during lactation (Figure 1). Groups A, B, and D showed an increase in diet and calorie intake from the beginning of lactation. However, while groups A and D maintained their intake, group B showed a decrease after the first week, with an intake similar to that of group C. The energy level of diets A and B (4.22 and $4.02 \mathrm{kcal} / \mathrm{g}$ ) differed from diets $\mathrm{C}$ and $\mathrm{D}$ 


\section{(3.55 and $3.83 \mathrm{kcal} / \mathrm{g})(\mathrm{P}<0.05)$.}

Analysis of spillage showed higher food waste in group $\mathrm{C}$ compared to the other groups. The average spillage throughout lactation was 10.7, 52.4 and $5.9 \mathrm{~g}$ for groups B, $\mathrm{C}$ and $\mathrm{D}$, respectively. There was no spillage in group A.

The intake of a low-calorie and lowprotein diet profoundly affected the weight of dams and litters from groups B and C, while the calorie intake limited the growth of D litters at 21 days compared with A litters, but had no effect on the weight of D dams. The difference in pup growth between the four groups showed an indirect relationship with dam weight at the end of the period. It is likely that protein restriction exerts its effect on milk protein through a reduction in amino acid supply, since protein and energy restriction has been shown to reduce milk production but not protein concentration. A decrease in lactose production may promote a decline in milk volume and thus increase milk fat and protein concentration. How a curtailed endogenous protein supply influences mammary carbohydrate metabolism is unclear, but if the endogenous amino acids were used to any extent as gluconeogenic precursors, a reduced supply would possibly limit the activity of the lactose synthesis complex (5).

In spite of a lower protein diet in groups $\mathrm{B}$ and $\mathrm{C}$, the similar caloric intake for groups $\mathrm{A}$ and $\mathrm{B}$ during the first five days of lactation showed a behavioral calorie compensation through carbohydrate content, which decreased progressively during lactation. The decrease in diet intake in groups $\mathrm{B}$ and $\mathrm{C}$ is due to a regulatory system involving gastrointestinal and metabolic aspects mediated by neural structures that are, at least in part, non-overlapping as suggested by Seeley et al. (6).

Feeding is under the control of a central feeding system that is regulated by a delicate balance of the interaction between monoamines and neuropeptides. Morley (7) has
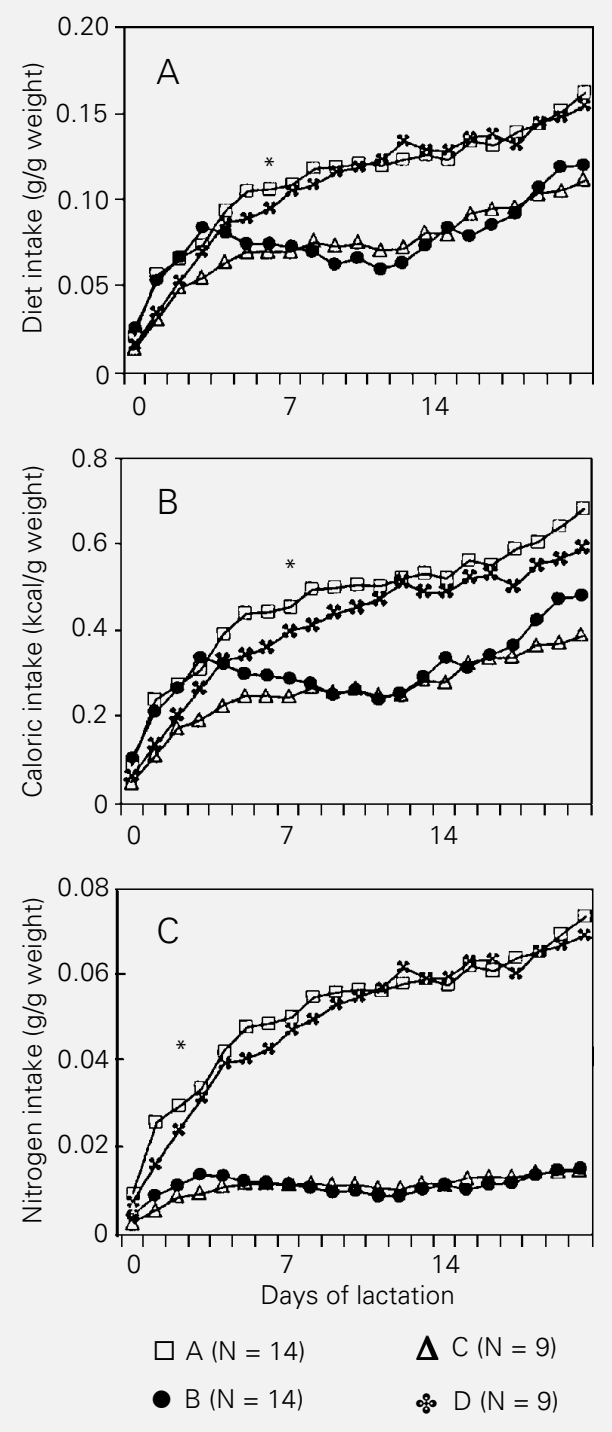

suggested that numerous peptides acting as neurotransmitters or hormonal peptides increase or decrease food intake. Food intake regulation predominantly involves the introduction of a variety of peripheral satiety systems that attempt to decrease the central feeding command system.

The basic physiological principle that governs the regulation of nutrient intake appears to be neither the fluctuation of energy level of the body nor energy content of ingested foods but the detection of the degree of depletion and repletion of essential nutrients (8). This involves a sequence of regula-
Figure 1 - Feeding performance ( $g$ food intake/g body weight) of dams during lactation. Values are the means for all rats receiving each diet on each day of lactation. $A$, Diet intake; $B$, caloric intake; $C$, nitrogen intake. ${ }^{*} \mathrm{P}<0.05$ for diets $A$ and $D$ compared to diets B and C (Kruskal-Wallis test and StudentNewman-Keuls test for multiple comparison). 
tory mechanisms of nutrient intake and several interactions within various aspects such as the action of cholecystokinin, glucagonlike peptide-1, corticosterone, neuropeptide $\mathrm{Y}$ and serotonin levels (9-12). Many neuropeptides have been proposed as central satiety factors, but few have an established physiological role. The fact that malnourished dams decrease their intake probably involves satiety processes in the control of feeding behavior in the rat.

A sequence of mechanisms may be involved in the metabolic regulation of intake.
For example, cholecystokinin, which is released from the duodenum in response to food passing through the gastrointestinal tract, causes reduced food intake in a variety of species. Neuropeptide Y predominantly increases carbohydrate intake in rats by a direct action within the central nervous system (13).

Further work is necessary to clarify the action of hormones, neuropeptides and the neural pathway linking the gastrointestinal and satiety control systems when proteincalorie levels of diets differ during lactation.

\section{References}

1. Strubbe JH \& Gorissen J (1980). Meal patterning in the lactating rat. Physiology and Behavior, 25: 775-777.

2. Pine AP, Jessop NS, Allan GF \& Oldham JD (1994). Maternal protein reserves and their influence on lactational performance in rats. 4. Tissue protein synthesis and turnover associated with mobilization of maternal protein. British Journal of Nutrition, 72: 831-844.

3. American Institute of Nutrition Rodent Diets (1977). Report of the American Institute of Nutrition ad hoc Committee on standards for nutritional studies. Journal of Nutrition, 107: 1340-1348.

4. Association of Official Agricultural Chemists (1965). In: Horwitx W (Editor), Official Methods of Analysis. Washington, DC, 957-958.
5. Pine AP, Jessop NS \& Oldham JD (1994) Maternal protein reserves and their influence on lactational performance in rats. 3 The effects of dietary protein restriction and stage of lactation on milk composition. British Journal of Nutrition, 72: 815830.

6. Seeley RJ, Grill HJ \& Kaplan JM (1994). Neurological dissociation of gastrointestinal and metabolic contributions to meal size control. Behavioral Neuroscience, 108: 347-352.

7. Morley JE (1987). Neuropeptide regulation of appetite and weight. Endocrine Reviews, 8: 256-287.

8. Poothullil JM (1995). Oral satiation and regulation of intake. Physiology and Behavior, 57: 349-352.

9. Hsiao S, Wang CH \& Schallert T (1979). Cholecystokinin, meal pattern, and the intermeal interval: can eating be stopped before it starts? Physiology and Behavior, 23: $909-914$
10. Turton MD, O'Shea D, Gunn I, Beak SA Edwards CMB, Meeran K, Chi SJ, Taylor GM, Health MM, Lambert PD, Wilding JPH, Smith DM, Ghatei MA, Herbert J \& Bloom SR (1996). A role for glucagon-like peptide-1 in the central regulation of feeding. Nature, 379: 69-72.

11. Boxwell J, Ayson $P$ \& Ramenovsk $M$ (1995). Growth and metabolic parameters in pups of undernourished lactation rats. Physiology and Behavior, 57: 469-475

12. Holder MD \& Huether G (1990). Role of prefeedings, plasma amino acid ratios and brain serotonin levels in carbohydrate and protein selection. Physiology and Behavior, 47: 113-119.

13. Morley JE (1995). The role of peptides in appetite regulation across species. American Zoologist, 35: 347-445 